\title{
Proprioceptive Control of Extensor Activity during Fictive Scratching and Weight Support Compared to Fictive Locomotion
}

\author{
Marie-Claude Perreault, Manuel Enriquez-Denton, and Hans Hultborn \\ Department of Medical Physiology, The Panum Institute, University of Copenhagen, DK-2200 Copenhagen, Denmark
}

At rest, extensor group I afferents produce oligosynaptic inhibition of extensor motoneurons. During locomotor activity, however, such inhibition is replaced by oligosynaptic excitation. Oligosynaptic excitation from extensor group I afferents plays a crucial role in the regulation of extensor activity during walking. In this study we investigate the possibility that this mechanism also regulates extensor muscle activity during other motor tasks.

We show that the reflex pathways responsible for extensor group I oligosynaptic excitation during fictive locomotion can be activated during both fictive scratching and fictive weight support (tonic motor activity induced by contralateral scratching). These observations suggest that the excitatory group I oligosynaptic reflex pathways are open for transmission during several forms of motor activities. We also show that extensor group I input during fictive scratching can affect the amplitude and the timing of extensor activity in a pattern similar to that observed during locomotion. Most likely these effects involve the activation of the excitatory group I oligosynaptic reflex pathways. Accordingly, it is suggested that extensor group I oligosynaptic excitation during motor activities other than locomotion is also used to regulate extensor muscle activity. Furthermore, the similarity of effects from extensor group I input on the rhythmicity during scratching and locomotion supports the hypothesis that both rhythms are generated by a common network.

Key words: primary muscle spindles; Golgi tendon organs; spinal cord; sensory feedback; rhythm generating networks; motoneuron; motor control
In the quiescent cat, activation of extensor group I afferents (which include afferents from both muscle spindle primaries and Golgi tendon organs) induces oligosynaptic reflexes in extensor motoneurons that are predominantly inhibitory [autogenic inhibition (Granit 1950; Eccles et al., 1957); nonreciprocal group I inhibition (Jankowska 1992)]. However, during locomotion, such inhibition is replaced by oligosynaptic excitation (for review, see Pearson, 1995; Hultborn et al., 1998). There are two oligosynaptic reflex pathways that contribute to extensor group I afferent excitation of extensor motoneurons; the disynaptic (McCrea et al., 1995; Angel et al., 1996) and the polysynaptic (Gossard et al., 1994) group I pathways. Although afferents from Golgi tendon organs (group Ib) probably provide the dominating input to these pathways (Gossard et al., 1994; McCrea et al., 1995; Angel et al., 1996), there is also a significant contribution from primary muscle spindle afferents (group Ia) (McCrea et al., 1995; Angel et al., 1996).

The disynaptic and the polysynaptic group I reflex pathways represent important sources of excitatory feedback during locomotion and provide a means by which extensor muscle activity

\footnotetext{
Received June 28, 1999; revised Sept. 27, 1999; accepted Sept. 28, 1999.

This work was supported by grants from the Danish Medical Research Council, the Lundbeck Foundation, the NOVO Nordisk Foundation, and the Human Frontier Science Program Organization. We thank the following people for their assistance: Mrs. Lillian Grøndahl and Conni Temdrup for their help during the experiments, Allan Djørup with computers, Kurt Helmer with mechanics, and Egil Gudbrandsen and the late Jan Nielsen with electronics. We would also like to thank Drs. Morten Raastad and Matthew Tresch for their useful comments.

Correspondence should be addressed to M.-C. Perreault, Department of Physiology, University of Oslo, P.O. Box 1103, Blindern, N-0317 Oslo, Norway. E-mail: m.c.perreault@basalmed.uio.no.

Dr. Denton's present address: Institute of Biomedical and Life Sciences, Division of Neuroscience and Biomedical Systems, West Medical Building, University of Glasgow, Glasgow G12 8QQ, Scotland.

Copyright (C) 1999 Society for Neuroscience 0270-6474/99/1910966-11\$05.00/0
}

can be generated, reinforced, and prolonged (Conway et al., 1987; Pearson and Collins, 1993; Guertin et al., 1995; Whelan et al., 1995; Whelan and Pearson, 1997; Hiebert and Pearson, 1999). Such excitatory feedback from extensor group I afferents may also be used to control extensor muscle activity during motor tasks other than locomotion. It has been proposed, for instance, that group I excitatory feedback may help to regulate the duration of extensor activity during scratching (Kuhta and Smith, 1990; Carlson-Kuhta and Smith, 1994) and reinforce weight-bearing muscle activity during standing (Pratt, 1995). Although there is evidence supporting the existence of excitatory feedback from extensor group I afferents during nonlocomotor behaviors (Pratt, 1995; Prochazka et al., 1997a,b), it has yet to be shown that the oligosynaptic group I reflex pathways described above are involved.

In this study, we investigated the ability of ankle extensor group I afferents to evoke oligosynaptic EPSPs in hindlimb extensor motoneurons during fictive scratching (Deliagina et al., 1975, 1981) and "fictive weight support". In contrast to fictive scratching, fictive weight support is mainly a tonic activity and refers to the tonic activity in contralateral hindlimb extensor muscles during real scratching (Sherrington, 1910). We also examined the effects of extensor group I afferent stimulation on the scratching rhythm.

Some of the present results have been presented in abstract form (Perreault et al., 1997).

\section{MATERIALS AND METHODS}

Preparation. Data were obtained from 19 cats (1.9-3.5 kg). After anesthesia with halothane-nitrous oxide $\left(2-3 \%\right.$ halothane, $70 \% \mathrm{~N}_{2} \mathrm{O}$, and $30 \% \mathrm{O}_{2}$ ), the animals were intubated, and cannulas were inserted in the jugular vein and carotid artery for administration of fluid and drugs and 


\section{A FICTIVE SCRATCHING}

FICTIVE WEIGHT SUPPORT
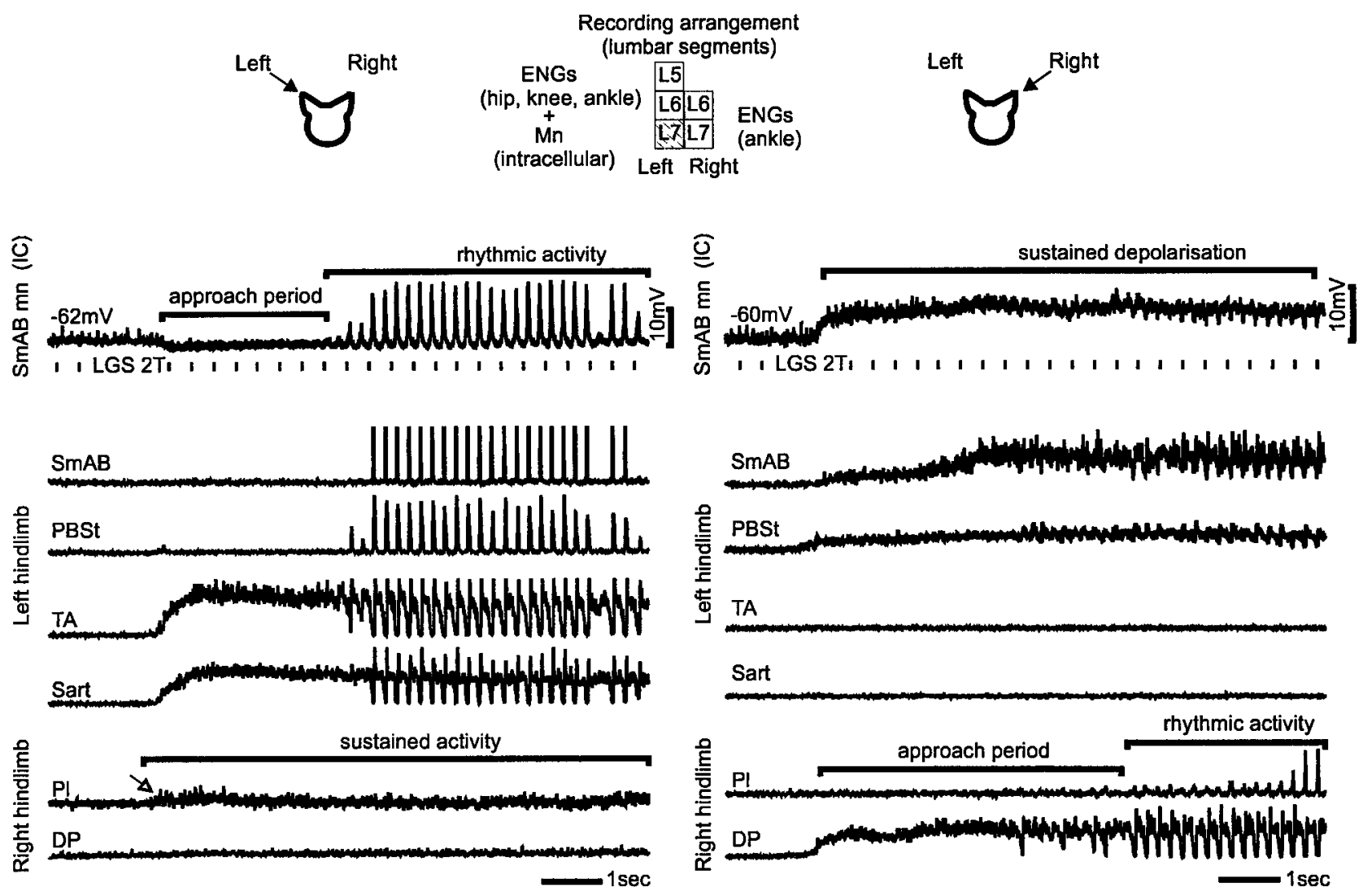

Figure 1. Motoneuronal activities during fictive scratching and weight support. Top to bottom, intracellular recording from an SmAB motoneuron (top trace), ENG recordings from the left hindlimb extensor $(\operatorname{SmAB})$, flexor (Sart, TA), and hip extensor/knee flexor (PBSt) nerves (middle four traces) and ENG recordings from the right hindlimb extensor $(P l)$ and flexor $(D P)$ nerves (bottom two traces). A, Fictive scratching was induced by manual stimulation of the left pinna and monitored with both intracellular recording from an extensor motoneuron in the left spinal cord (insert) and ENG recordings from left hindlimb nerves. Fictive scratching consisted of two periods: (1) an initial approach period during which extensor motoneurons $(S m A B)$ were tonically hyperpolarized and hip, knee, and ankle flexor nerves (Sart, $T A$ ) fired tonically, and (2) a rhythmic period during which the bursts of activity in hip (SmAB, PBSt) and ankle extensors $(M G, L G S$; data not shown) alternated with bursts in hip (Sart) and ankle (TA) flexors. In the right hindlimb, sustained activity was seen in Pl extensor nerve (arrow). B, Fictive weight support was induced by stimulation of the right pinna so it could be monitored with the same intracellular and left hindlimb ENG recordings as in $A$. The tonic increase in extensor activity during fictive weight support was generally more pronounced in hip ( $S m A B$ and $P B S t$ ) than in ankle extensors (data not shown). The intracellular record during fictive weight support shows that sustained depolarization of the extensor motoneuron was accompanied by small, cyclic reductions in membrane potential as rhythmic scratching activity appeared in the right hindlimb extensors. In both panels, the vertical bars below the intracellular waveform indicate single shock stimulation to LGS nerve.

blood pressure monitoring. Atropine $(0.1 \mathrm{mg} / \mathrm{kg}$, s.c.) and dexamethasone $(1 \mathrm{mg} / \mathrm{kg}$, i.v. $)$ were given at the beginning of the experiment while buffer solution $\left(10 \%\right.$ dextrose and $\left.1.7 \% \mathrm{NaHCO}_{3}\right)$ was infused continuously $(4.5 \mathrm{ml} / \mathrm{hr})$. The following nerves from the left hindlimb were cut and dissected for recording or stimulation: the flexor nerves sartorius (Sart, with both medial and lateral branches) and tibialis anterior (TA), the extensor nerves semimembranosus and anterior biceps (SmAB), medial gastrocnemius (MG), and/or lateral gastrocnemius plus soleus (GS and/or LGS) and plantaris ( $\mathrm{Pl}$ ) and, the bifunctional nerves posterior biceps-semitendinosus (PBSt), quadriceps $(\mathrm{Q}$ with the rectus femoris portion), and flexor digitorum and hallucis longus (FDHL). The Q and Sart nerves were placed in cuff electrodes, and the other nerves were mounted on bipolar hook electrodes. From the right limb, GS or Pl and TA or DP (tibialis anterior plus extensor digitorum longus) nerves were mounted. In all experiments, the remaining femoral, sciatic, and obturator nerve branches, and the tendons around the hips, were cut bilaterally. After a laminectomy exposing L4-S1 spinal cord segments, animals were transferred to a rigid frame, and the head was positioned in a stereotaxic apparatus. Then, a second laminectomy exposing C1-C2 segments and a precollicular-postmammillary decerebration (with all brain tissue rostral to the transection removed) were performed. Decrease of the blood pressure to $<80 \mathrm{mmHg}$ was counteracted by injection of Dextran. Anesthesia was then discontinued, and the animal was paralyzed with pancuronium bromide (Pavulon; $4 \mathrm{mg} \cdot \mathrm{kg}^{-1} \cdot \mathrm{hr}^{-1}$ ). The expired $\mathrm{CO}_{2}$ was maintained between 3.0 and $5.0 \%$ by artificial ventilation. Animal temperature was kept at $\sim 38^{\circ} \mathrm{C}$ by servo-controlled infrared lamps. The experiments were approved by the National Ethics Committee in Denmark.

Fictive motor programs. The motor programs studied include fictive scratching (Fig. $1 A$ ), fictive weight support (Fig. $1 B$ ), and fictive locomotion. Fictive weight support refers to the tonic activity of extensors seen in the hindlimb opposite to that performing scratching (Sherrington, 1910). After topical application of D-tubocurarine (0.1-0.3\%) at $\mathrm{C} 1$ and $\mathrm{C} 2$ dorsal root entry zones (Domer and Feldberg, 1960), fictive scratching and weight support were induced in the left hindlimb by manual stimulation of the left and right pinna, respectively (Fig. 1, diagrams). Fictive locomotion was evoked by stimulation of the mesencephalic locomotor region (MLR; 100-200 $\mu \mathrm{A} ; 1 \mathrm{msec}$ pulses; $5-20 \mathrm{~Hz}$; Shik et al., 1966). In five cats, naloxone $(100 \mu \mathrm{g} / \mathrm{kg})$ and clonidine (50 $\mu \mathrm{g} / \mathrm{kg}$ ) were given to prolong the period over which locomotor activity could be induced (Pearson et al., 1992). 


\section{A Fictivelocomotion B Fictive SCRATCHING C Fictive Weliht SUPPORT}
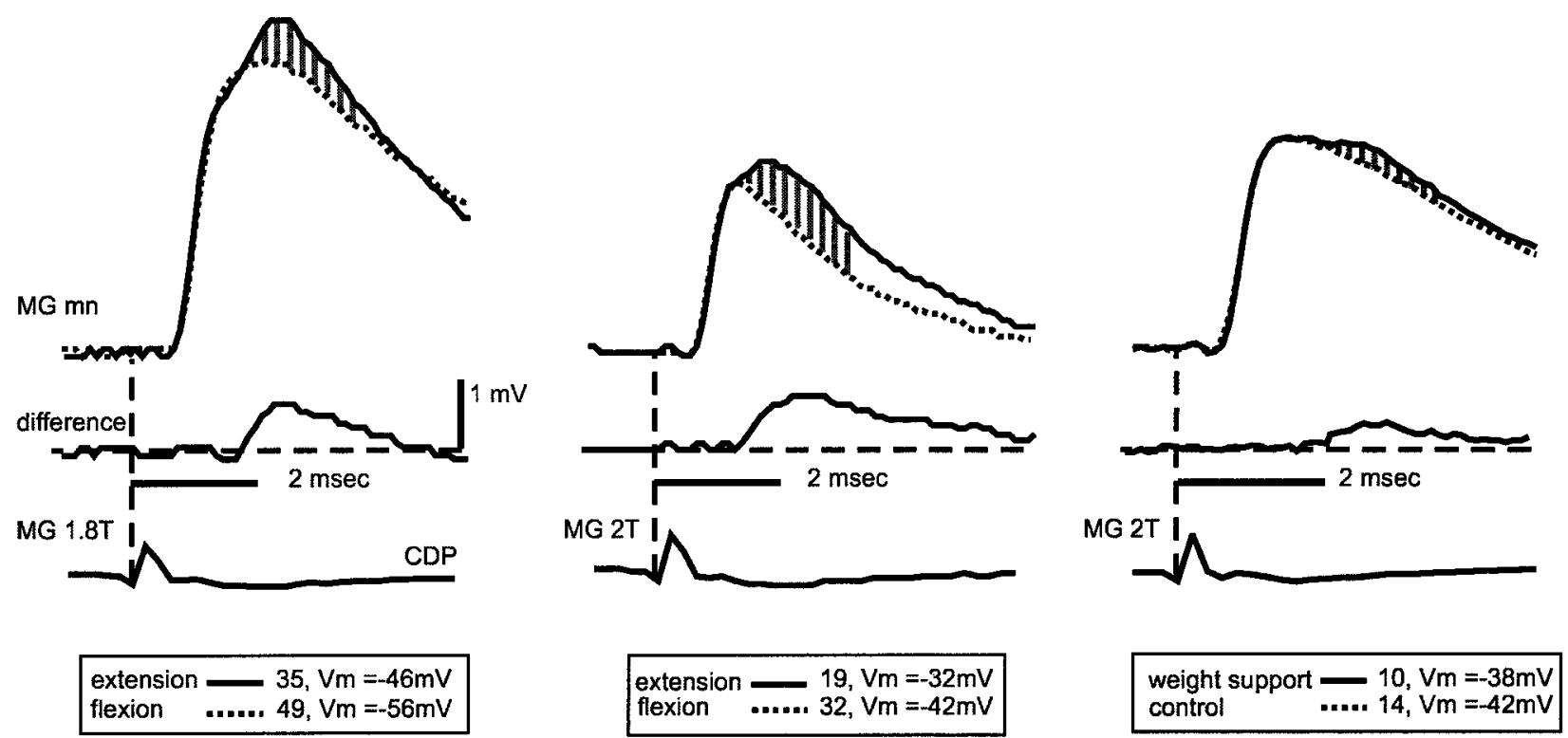

Figure 2. Ankle extensor group I afferents evoke disynaptic EPSPs not only during fictive locomotion but also during fictive scratching and weight support. The top two traces in $A-C$ are averaged intracellular recordings from an MG motoneuron, showing the group I disynaptic excitatory response (hatched areas) evoked by MG nerve stimulation during fictive locomotion, scratching, and weight support. During locomotion $(A)$ and scratching $(B)$, the superimposed traces are the averages during extension (solid trace) and flexion (dotted trace). In $C$, superimposed traces are from the averages during weight support (solid trace) and at rest (dotted trace). In all panels, the middle trace is the arithmetic difference between the top two traces. The bottom trace is the cord dorsum potential record of the arrival of the afferent volley (vertical dashed line). Number of trials used in the calculation of the averages and the value of the membrane potential are indicated.

Experimental protocols. Independently of the fictive motor program induced, intracellular recordings were obtained from antidromically identified extensor motoneurons innervating the left hindlimb (Fig. 1). Glass micropipettes (tip diameter, 1.2-2 $\mu \mathrm{m}$; resistance, 2-4 M $\Omega$ ) filled with the lidocaine derivative QX-314 in potassium acetate $(2 \mathrm{M})$ were used. QX-314 blocks sodium spikes and may, in addition, reduce calcium currents [Talbot and Sayer (1996) in hippocampal neurons and Heckman and Lee (1998) in spinal motoneurons]. Thus, QX-314 limits the extent to which sodium and calcium currents could affect postsynaptic potentials.

Postsynaptic potentials were evoked by free-running $(3-5 \mathrm{~Hz})$ stimulation of ankle extensor nerves (1-3 pulses at 100-300 Hz). The strength of the peripheral nerve stimulation was expressed as multiple of the threshold $(T)$ for the most excitable afferent fibers to evoke cord dorsum potential (CDP) at the L4 or L7 segment. The central latencies of the PSPs were measured from the arrival of the earliest component of the cord dorsum group I afferent volley (Fig. 2). The effects of group I input on the fictive scratching rhythm were investigated using short (relative to the duration of the extension or flexion phase) trains of stimuli (10-25 pulses at $100-300 \mathrm{~Hz}$ ) to ankle extensor nerves. These trains were triggered from the onset of activity in one of the flexor (see Fig. 6) or extensor (see Fig. 7) nerves. In some experiments, the stimulation was delivered continuously throughout many cycles (see Fig. 5).

Analysis. Integrated and rectified electroneurograms (ENGs), stimulus markers (from the MLR and the peripheral nerve stimulation), AC (cord dorsum potentials and intracellular records)-, and DC-coupled recordings (intracellular records) were digitized at a rate of $500 \mathrm{~Hz}, 2,10$, and $5 \mathrm{kHz}$, respectively. All data were collected and analyzed on a Concurrent 5450 or a personal computer (PC) with software developed by the Winnipeg Spinal Cord Research Center to run under real time Unix (Concurrent) or QNX (PC).

The PSPs evoked by peripheral nerve stimulation were averaged before (control) and during each of the fictive motor programs. During fictive scratching and locomotion, the responses occurring during the flexion or the extension phases were averaged separately. From these averages we excluded the responses evoked during the transition between the two phases. During the initial postural period of scratching (Fig. $1 \mathrm{~A}$, approach period), the responses were analyzed only if the duration of this period allowed a minimum of seven stimuli. During fictive weight support, the responses were analyzed after the initial membrane potential depolarization had reached a tonic plateau (Fig. $1 B$ ).

The oligosynaptic EPSPs were frequently preceded by monosynaptic group Ia EPSPs (Figs. 2, 3). To reduce the effect of such contamination on the latencies and amplitudes estimates, we isolated the oligosynaptic EPSPs from the monosynaptic EPSP. This was done by subtracting the "contaminating" monosynaptic EPSP. The traces used for subtraction contained monosynaptic but no oligosynaptic EPSPs (control traces for example). Before subtraction, this monosynaptic EPSP was scaled to the peak amplitude of the "contaminating" monosynaptic EPSPs. The latencies and amplitudes of the oligosynaptic EPSPs were usually measured from the trace remaining after subtracting the trace in the absence of motor activity (control) (Figs. $2 C, 3 A-C$, "difference" trace). However, because disynaptic EPSPs appeared only during the extension phase of fictive locomotion and scratching, disynaptic EPSPs during extension phase were isolated by subtracting the trace during flexion (Fig. 2A,B). The statistics for the latencies and amplitudes are given as mean \pm SEM, and statistical tests for differences between the means were done by one-way ANOVA using the Dunnett method for multiple comparisons against a single control group $(\alpha<0.05$; Glantz, 1981). The statistics included only group I EPSPs of amplitudes $>200 \mu \mathrm{V}$ in response to single shock stimulation.

To analyze the effects of train stimulation on the timing of nerve activity during scratching, we measured (1) the duration of each ENG burst and each cycle (time between the onset of two consecutive ENG bursts) and (2) plotted these values against time (see Figs. 5C-E, 6C, $7 C, D)$. For the effects on the amplitude of the nerve activity, ENG bursts were averaged and aligned on the onset of the train of stimuli (see Figs. $6 B, 7 B$ ) or, in the case of continuous stimulation (see Fig. $5 B$ ), on the onset of the SmAB activity. 


\section{A fictive Locomotion}

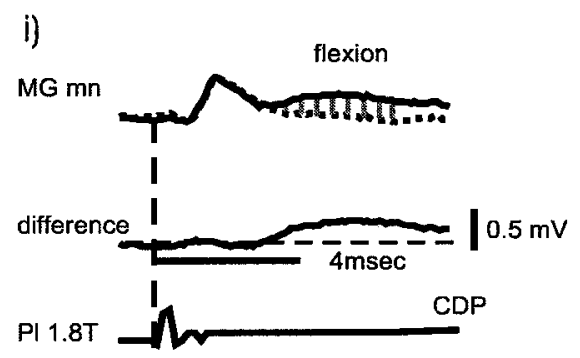

flexion $-206, \mathrm{Vm}=-56 \mathrm{mV}$

control $\cdots=32, \mathrm{Vm}=-55 \mathrm{mV}$

\section{B}
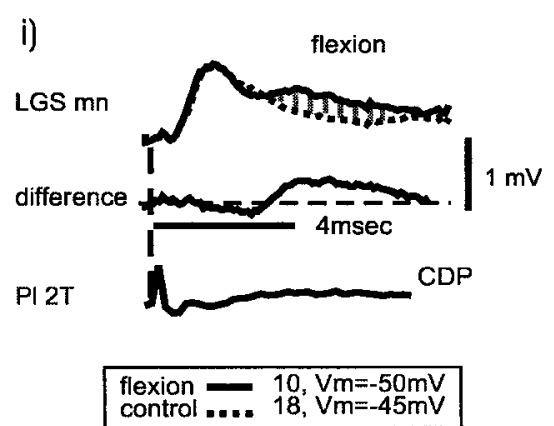

ii)

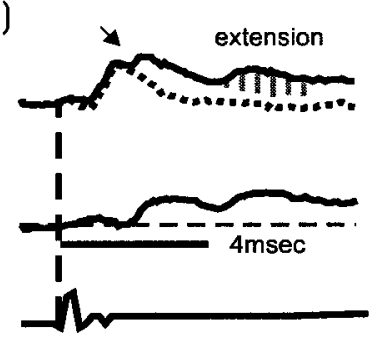

extension $-46, \mathrm{Vm}=-46 \mathrm{mV}$ control $\ldots . . .32, V m=-55 m V$
FICTIVE WEIGHT SUPPORT

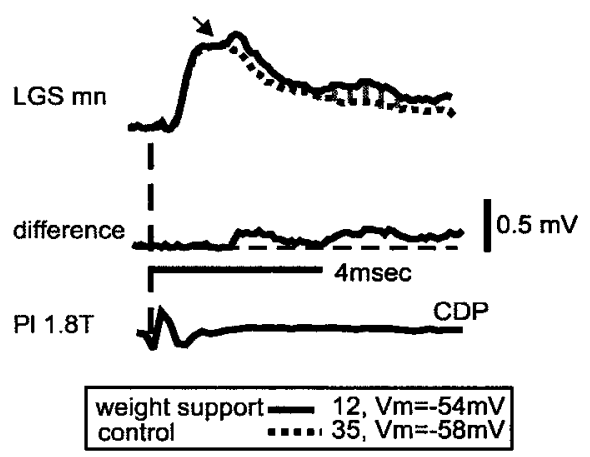

\section{FICTIVE SCRATCHING}

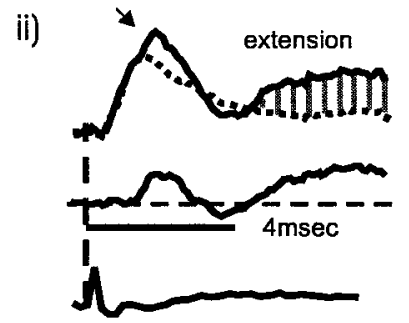
extension $8, \mathrm{Vm}=-40 \mathrm{mV}$ extension $18, V m=-40 m V$
control ... 18, $\mathrm{m}=-45 \mathrm{mV}$ iii)

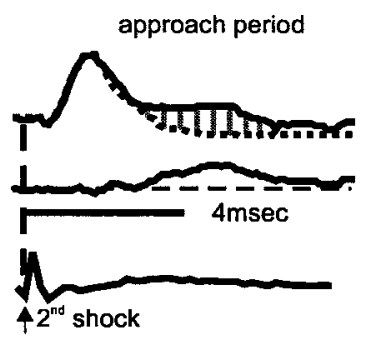

app. period $26, \mathrm{Vm}=-50 \mathrm{mV}$ control \#18, $v m=-45 m v$

Figure 3. Modulation of group I polysynaptic EPSPs during fictive locomotion, scratching, and weight support. Averaged intracellular recordings from three different motoneurons (1 MG and 2 LGS) showing polysynaptic group I EPSPs (hatched areas) evoked by ankle extensor stimulation during fictive locomotion $(A)$, scratching $(B)$, and weight support $(C)$. Note that when the stimulation was applied during the extension phase of either locomotion or scratching, or during weight support, disynaptic group I EPSPs were also evoked (arrows). For other details, see Figure 2.

\section{RESULTS}

\section{Motor pattern characteristics of fictive scratching and weight support}

Figure 1 shows the nerve activities induced in hindlimbs by manual stimulation of the left $(A)$ and the right $(B)$ pinna. Left pinna stimulation (diagram) induced fictive scratching in the left hindlimb. Fictive scratching was divided into two main periods (Deliagina et al., 1981); an initial tonic period and a rhythmic period $(3.2-6.0 \mathrm{~Hz})$ with alternating bursts of activity in extensors and flexors. The activity during the initial period was similar to that recorded during the hindlimb approach in the intact cat (Kuhta and Smith, 1990) and consisted in a tonic firing in flexor nerves (Fig. 1 $A$, TA and Sart; for intracellular records, see Berkinblit et al., 1980; Degtyarenko et al., 1998). We also found that during the approach period, extensor motoneurons were tonically hyperpolarized (Fig. $1 A$, intracellular record). Tonic hyperpolarization of extensors, which was seen in SmAB but also in MG and LGS (data not shown) motoneurons, was sometimes preceded by a short burst of activity (data not shown). Such extensor bursts before the approach period have also been recorded in intact cats that performed scratching from a standing position (Kuhta and Smith, 1990).

As described by Sherrington (1910), contralateral hindlimb extensors become tonically active to help cats support their weight during scratching. The sustained firing recorded in the Pl extensor nerve of the right hindlimb during fictive scratching (Fig. $1 \mathrm{~A}$; open arrow) shows that weight support activity can also be recorded in preparations without movement-related feedback. Fictive weight support was induced in the left hindlimb (Fig. 1B) by manual stimulation of the right pinna (Fig. 1, diagram). As shown by the intracellular record (same SmAB motoneuron as in $A$ ), extensor motoneurons were tonically depolarized during fictive weight support. In the extensor nerves, tonic firing was usually larger in SmAB and PBSt than in ankle nerves. Before the onset of weight support, bursts of activity of $\sim 300 \mathrm{msec}$ (data not shown) were sometimes seen in the PBSt and in the flexor nerves. These flexor bursts may correspond to the yield of the limb when cats switch from quadrupedal to tripodal stance position to perform scratching. The intracellular record in Figure $1 B$ also shows cyclic reductions in membrane potential as scratching rhythmic activity appeared in the opposite hindlimb (see right hindlimb ENGs). These cyclic reductions were always of small amplitude $(\leq 2 \mathrm{mV})$ and never reached $>20 \%$ of the amplitude of membrane potential oscillations seen during fictive scratching.

\section{Database for intracellular recordings and observations on monosynaptic EPSPs and nonreciprocal IPSPs}

The synaptic responses evoked by electrical stimulation (one to three shocks, $2 \mathrm{~T}$ ) of ankle extensor nerves were examined in all 23 extensor motoneurons (12 experiments) recorded during fic- 


$\begin{aligned} & \text { Table 1. Number and type of motoneurons recorded during fictive } \\
& \text { locomotion }(\mathrm{L}) \text {, scratching }(\mathrm{S}), \text { and weight support }(\mathrm{W})\end{aligned}$
\begin{tabular}{ll} 
Motoneurons & Fictive motor programs \\
\hline $12 \mathrm{MG}$ & $3(\mathrm{~L}+\mathrm{S}+\mathrm{W}), 3(\mathrm{~L}+\mathrm{S}), 1(\mathrm{~L}+\mathrm{W}), 1(\mathrm{~S}+\mathrm{W}), 2(\mathrm{~S}), 2(\mathrm{~L})$ \\
$7 \mathrm{LGS}$ & $3(\mathrm{~L}+\mathrm{S}+\mathrm{W}), 2(\mathrm{~S}+\mathrm{W}), 1(\mathrm{~S}), 1(\mathrm{~L})$ \\
$1 \mathrm{Pl}$ & $1(\mathrm{~L})$ \\
$3 \mathrm{SmAB}$ & $1(\mathrm{~L}+\mathrm{S}+\mathrm{W}), 1(\mathrm{~L}+\mathrm{S}), 1(\mathrm{~S}+\mathrm{W})$ \\
Total $=23$ &
\end{tabular}

tive locomotion ( $n=16)$, scratching $(n=18)$, and weight support $(n=12)$. In most cases $(n=16)$, the motoneurons were recorded during at least two different fictive programs (Table 1, Fig. 2). Seven motoneurons were recorded during locomotion, scratching, and weight support $(\mathrm{L}+\mathrm{S}+\mathrm{W})$, four during locomotion and scratching $(\mathrm{L}+\mathrm{S})$, four during scratching and weight support ( $\mathrm{S}$ $+\mathrm{W})$, and one during locomotion and weight support $(\mathrm{L}+\mathrm{W})$.

In the present experiments, the responses induced by ankle extensor nerve stimulation often included monosynaptic group Ia EPSPs (17 of 23 extensor motoneurons; Figs. 2, 3). During fictive locomotion and scratching, monosynaptic EPSPs were of smaller amplitude than at rest with mean amplitudes equal to $74 \pm 8 \%$ $(n=12)$ and $73 \pm 7 \%(n=11)$ of control, respectively. Monosynaptic EPSPs showed little phasic modulation within the locomotor or the scratching cycle (the difference between the mean amplitudes during the flexion and extension phases was $<10 \%$ during both conditions). During fictive weight support, monosynaptic EPSPs had a mean amplitude equal to $87 \pm 10 \%$ of control $(n=6)$.

Nonreciprocal IPSPs in extensor motoneurons after extensor group I afferent stimulation are routinely replaced by group I oligosynaptic EPSPs during fictive locomotion (Gossard et al., 1994; McCrea et al., 1995; Angel et al., 1996). Occasionally, however, reduced amplitude nonreciprocal group I IPSPs may be seen together with oligosynaptic EPSPs (Gossard et al., 1994; McCrea et al., 1995; Angel et al., 1996). In the present study, a mixture of oligosynaptic IPSPs and EPSPs was seen in 5 of 23 extensor motoneurons during locomotion (3 of 16), scratching (3 of 18), and weight support (3 of 12).

\section{Oligosynaptic group I EPSPs}

\section{Disynaptic EPSPS}

Stimulation of group I afferents in ankle extensor nerves evoked disynaptic EPSPs in extensor motoneurons during fictive locomotion, scratching, and weight support. As described by others (Schomburg and Behrends, 1978; Shefchyk et al., 1984; McCrea et al., 1995; Angel et al., 1996; Degtyarenko et al., 1998), disynaptic EPSPs (latency, $<2 \mathrm{msec}$ ) during fictive locomotion were evoked during the extension phase of the cycle. An example is shown in Figure $2 A$, in which EPSPs were induced in an MG motoneuron by group I strength $(\leq 2 \mathrm{~T})$ stimulation to $\mathrm{MG}$ extensor nerve. The disynaptic EPSP was seen as an additional depolarization (shaded area) arising at the peak of the monosynaptic group Ia EPSP. The latency of this averaged disynaptic EPSP was $1.7 \mathrm{msec}$ as measured from the trace representing the arithmetic difference (middle trace) between the averaged trace during extension (solid trace) and flexion (dotted trace). In Figure $2 B$, the same MG motoneuron was recorded during fictive scratching. Again, MG nerve stimulation induced a depolarization at a latency of 1.4 msec, i.e., still within the disynaptic range. As was also observed during fictive locomotion, this disynaptic group I EPSP appeared only when the motoneuron was depolarized (extension phase). Disynaptic group I EPSPs were absent not only during flexion but also during the approach period of fictive scratching (nine motoneurons tested from five different experiments). Even when using double shock stimulation (Fig. 3Biii), we were not able to detect disynaptic group I EPSPs during the approach period. Figure $2 C$ shows that $M G$ nerve stimulation during fictive weight support also induced short latency $(1.7 \mathrm{msec})$ EPSPs.

Overall, disynaptic group I EPSPs during fictive locomotion (mean latency, $1.78 \pm 0.04 \mathrm{msec}$; Fig. $4 A_{1}$ ) were seen in 10 of 16 extensor motoneurons (6 MG and 4 LGS), with amplitudes ranging from 342 to $1151 \mu \mathrm{V}$ (mean, $566 \pm 75 \mu \mathrm{V}$; Fig. $4 A_{2}$ ). During fictive scratching, disynaptic group I EPSPs were seen in 11 of 18 extensor motoneurons (6 MG and 5 LGS). They had a mean latency of $1.67 \pm 0.06 \mathrm{msec}$ (Fig. $4 A_{1}$ ) and amplitudes ranging from 223 to $2534 \mu \mathrm{V}$ (mean, $787 \pm 200 \mu \mathrm{V}$; Fig. $4 A_{2}$ ). The difference in the mean latency during the two conditions was not statistically significant ( $\alpha<0.05$; see Materials and Methods). The incidence of group I disynaptic EPSPs during fictive scratching $(61 \%$; 11 of 18 motoneurons) was also similar to that during fictive locomotion (62\%; 10 of 16). During fictive weight support, short latency group I EPSPs (mean latency, $1.92 \pm 0.07$ msec; Fig. $4 A_{1}$ ) were seen in four motoneurons (1 MG and 3 LGS) with amplitudes ranging from 242 to $555 \mu \mathrm{V}$ (mean, $392 \pm 63 \mu \mathrm{V}$; Fig. $4 A_{2}$ ). Although some of these had slightly longer latencies than during fictive locomotion, the difference in mean latencies was not significant. The incidence of disynaptic group I EPSPs during fictive weight support (33\%; 4 of 12 motoneurons) was lower than during fictive locomotion. It is possible, however, that this incidence may be an underestimate because positive deflections at latencies between 1.6 and 2.0 msec but with amplitudes below our detection criteria ( $>200 \mu \mathrm{V}$; see Materials and Methods) were seen in four motoneurons. If these deflections were genuine evoked disynaptic group I EPSPs, the estimated incidence would be $67 \%$ ( 8 of 12) and similar to that during fictive locomotion and scratching.

\section{Polysynaptic EPSPS}

Extensor group I EPSPs of longer latency and slower rising phase than the disynaptic group I EPSPs were also induced in extensor motoneurons during fictive locomotion, scratching, and weight support. During fictive locomotion, such polysynaptic group I EPSPs have been studied mainly using train stimulation of three to seven shocks (Gossard et al., 1994; McCrea et al., 1995). However, polysynaptic group I EPSPs induced by single shock stimulation have been reported occasionally (Gossard et al., 1994; Angel et al., 1996). In the present study, we only analyzed polysynaptic EPSPs evoked by single stimuli.

In Figure $3 A$, polysynaptic EPSPs (hatched areas) during fictive locomotion were recorded in a MG motoneuron after stimulation of the Pl extensor nerve. The averages during flexion and extension (panels $i$, ii, solid traces) are superimposed on the average in the absence of locomotion (control, dotted traces). During flexion, the polysynaptic EPSP arose from the falling part of the monosynaptic EPSP. Its latency was $3.7 \mathrm{msec}$ i.e., within the range of latencies of 3.5-4.0 msec reported by Gossard et al. (1994). During extension, single shock stimulation rarely elicited polysynaptic EPSPs. The example shown in Figure $3 A$ was the only exception. This polysynaptic EPSP was preceded by a disynaptic group I EPSP (arrow) and occurred at a longer latency than during flexion $(4.3 \mathrm{msec})$. Overall, during fictive locomotion, 
$A_{1}$

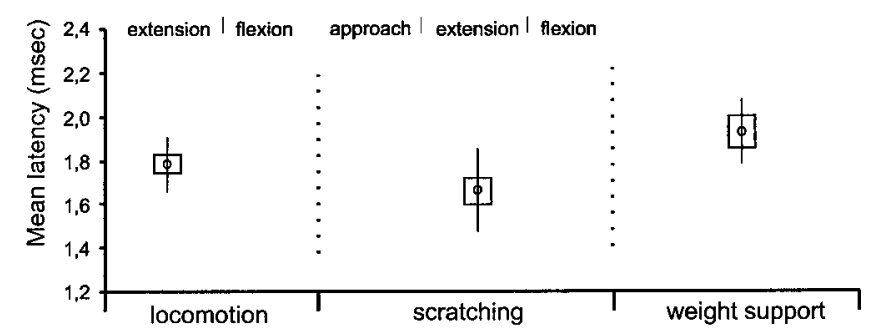

$\mathrm{B}_{1}$

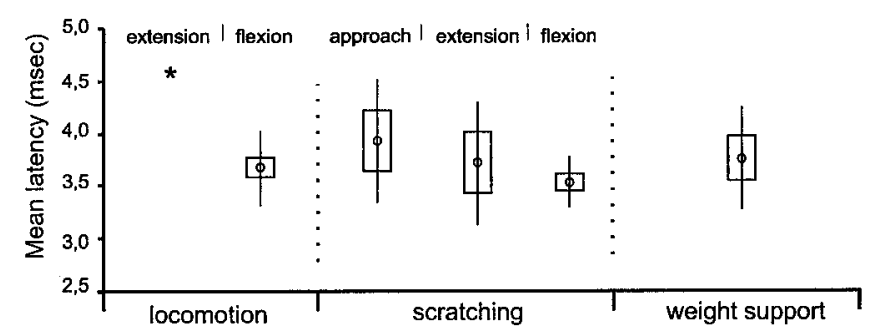

$\mathrm{A}_{2}$

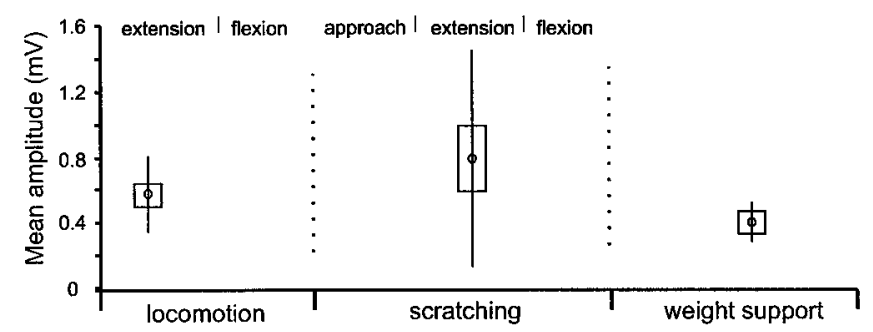

$\mathrm{B}_{2}$

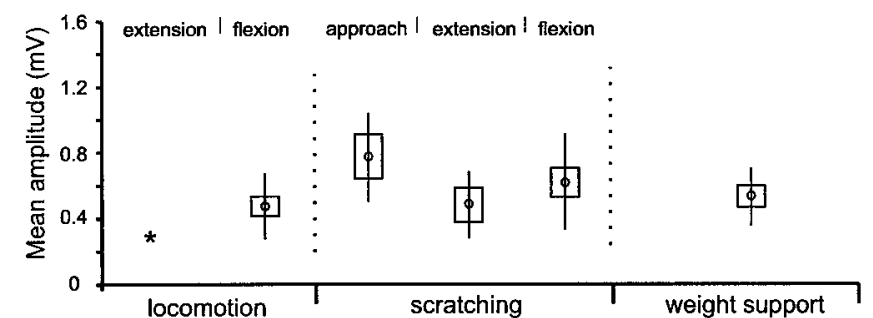

Figure 4. Mean latency and amplitude of disynaptic and polysynaptic group I EPSPs during fictive locomotion, scratching, and weight support. The mean latency and amplitude during fictive locomotion, scratching, and weight support are shown both for the disynaptic $\left(A_{1}, \mathrm{~A}_{2}\right)$ and the polysynaptic group I EPSPs $\left(\mathrm{B}_{1}, B_{2}\right)$. The values during the different phases of locomotion and scratching are indicated separately. The means (open circles) are shown with their corresponding SEs (rectangular boxes). SDs are also displayed (vertical bars). The asterisks indicate single observation.

polysynaptic group I EPSPs after single shock stimulation were evoked in 14 of 16 motoneurons (8 MG, 4 LGS, $1 \mathrm{Pl}$, and 1 $\mathrm{SmAB}$ ). Their mean latency was $3.66 \pm 0.10 \mathrm{msec}$ (Fig. $4 B_{1}$ ), and their amplitudes ranged from 264 to $817 \mu \mathrm{V}$ (mean, $468 \pm 54 \mu \mathrm{V}$; Fig. $4 B_{2}$ ).

During fictive scratching, polysynaptic group I EPSPs were evoked in 11 of 18 motoneurons (6MG, 4 LGS, and 1 SmAB). An example is shown in Figure $3 B$ where $\mathrm{Pl}$ nerve stimulation induced polysynaptic group I EPSPs in an LGS motoneuron during flexion ( panel $i$ ), extension ( panel ii), and approach period ( panel iii). The latency of the polysynaptic EPSP during the flexion and the extension phases was 3.5 and $4.8 \mathrm{msec}$, respectively. During the approach period, the EPSP reached an amplitude $>200 \mu \mathrm{V}$ only after two shocks (Fig. 3Biii, upward arrow). Overall, polysynaptic group I EPSPs during fictive scratching were encountered more often during flexion ( $n=10$ of 11$)$ than during extension ( $n=5$ of 11$)$ or during the approach period $(n=4$ of 9$)$. During the extension phase, polysynaptic EPSPs were preceded by disynaptic group I EPSPs in four of the motoneurons. As shown in Figure $4, B_{1}$ and $B_{2}$, polysynaptic EPSPs during flexion had a mean latency of $3.53 \pm 0.07 \mathrm{msec}$ and amplitudes ranging from 210 to $1222 \mu \mathrm{V}$ (mean, $614 \pm 93 \mu \mathrm{V}$ ). During extension, they had a mean latency of $3.74 \pm 0.27 \mathrm{msec}$ and amplitudes ranging from 222 to $700 \mu \mathrm{V}$ (mean, $472 \pm 105 \mu \mathrm{V}$ ). During the approach period, polysynaptic group I EPSPs (mean latency, $3.92 \pm 0.29$ msec) had amplitudes ranging from 382 to $986 \mu \mathrm{V}$ (mean, $765 \pm$ $133 \mu \mathrm{V}$ ). The difference between these mean latencies was not significant. Similarly, there was no significant difference between the mean latency during the different phases of scratching and the mean latency during the flexion phase of locomotion.

During fictive weight support, polysynaptic group I EPSPs were recorded in 6 of 12 motoneurons (1 MG, 4 LGS, and $1 \mathrm{SmAB})$. In the example shown in Figure $3 C$, Pl nerve stimulation induced a polysynaptic EPSP in an LGS motoneuron at $3.9 \mathrm{msec}$. In this and one other motoneuron, polysynaptic group I EPSPs during fictive weight support were preceded by disynaptic group I EPSPs $>200$ $\mu \mathrm{V}$. Polysynaptic group I EPSPs during fictive weight support had a mean latency of $3.75 \pm 0.20 \mathrm{msec}$ (Fig. $4 B_{1}$ ) and amplitudes ranging from 250 to $705 \mu \mathrm{V}$ (mean, $523 \pm 71 \mu \mathrm{V}$; Fig. $4 B_{2}$ ). The mean latency during fictive weight support was not significantly different from the mean latency during the flexion phase of locomotion.

Thus, in agreement with previous reports using trains of stimuli (Gossard et al., 1994; McCrea et al., 1995), polysynaptic EPSPs after single shock stimulation to extensor group I afferents during fictive locomotion were encountered most frequently during the flexion phase (incidence of $87 \%$ ). This was also the case during fictive scratching (incidence of 56\% during flexion, $28 \%$ during extension, and 22\% during approach). During fictive weight support, the incidence of group I polysynaptic EPSPs $(50 \%)$ was higher than during the extension phase of locomotion and scratching. The levels of depolarization of extensor motoneurons during these three conditions were often in the same range and thus, depolarization per se, is probably not the only determining factor for the incidence of group I oligosynaptic EPSPs (see Discussion).

\section{Effects of extensor group I input on the scratching rhythm}

To determine the effect of the group I reflex activation during fictive scratching, trains of stimuli were delivered to ankle extensor nerves at frequencies similar to the firing frequencies of muscle group Ia afferents during scratching (Feldman et al., 1977; Loeb et al., 1985). In the preliminary experiments, stimulation of ankle extensor nerves was applied continuously over many scratching cycles (five experiments). During the recording session 


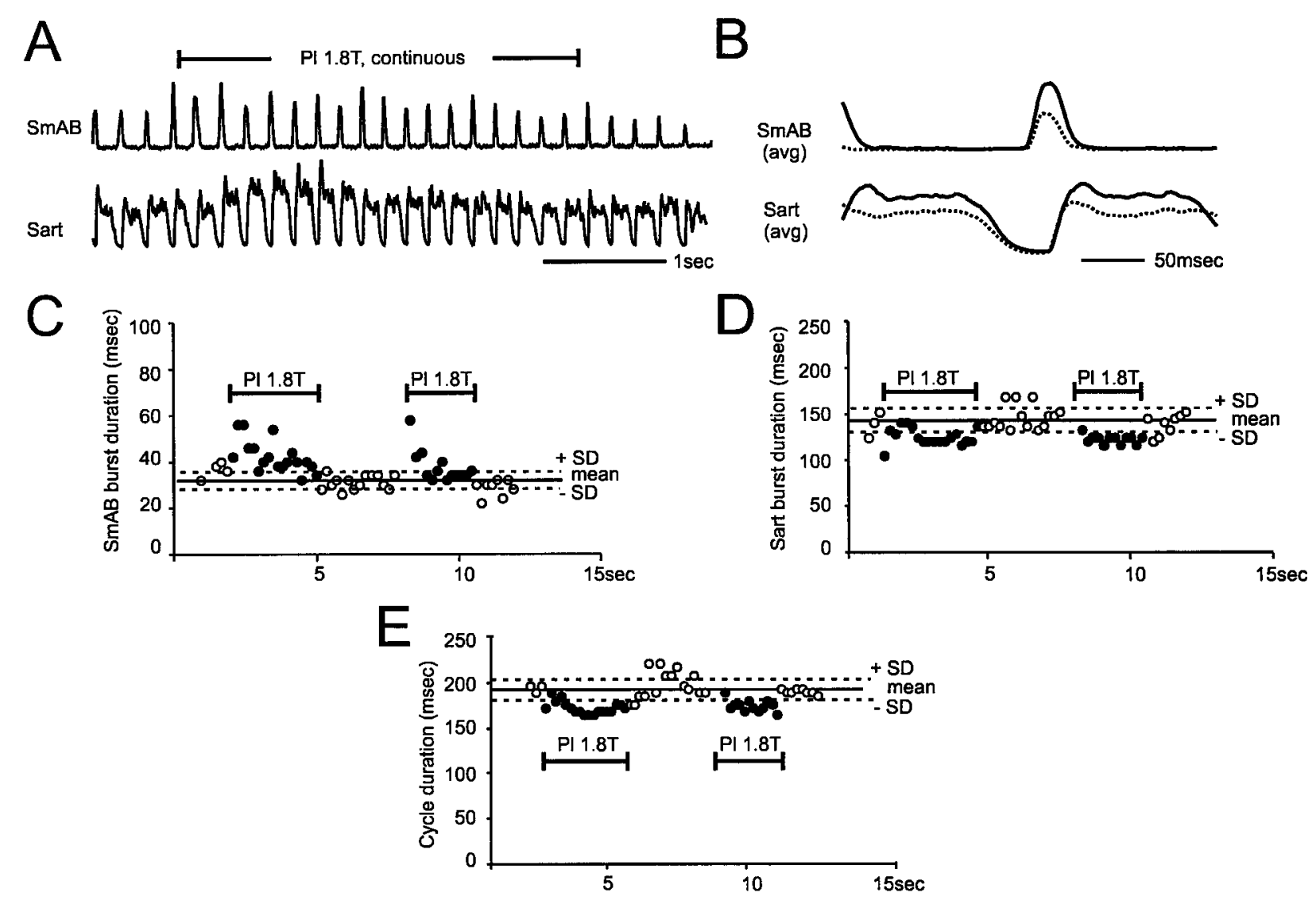

Figure 5. Continuous activation of ankle extensor group I afferents increases the frequency of the scratching rhythm. $A$, Pl nerve was stimulated continuously for $\sim 3 \mathrm{sec}$ during scratching. $B$, The averages during $(n=18$; solid trace $)$ and in the absence $(n=18$; dashed trace $)$ of stimulation showing that bursts in SmAB were increased both in amplitude and duration whereas the bursts in Sart were increased in amplitude but reduced in duration. After the stimulation, the bursts in SmAB and Sart returned to their original duration $(C$ and $D)$. Similar effects were seen when continuous stimulation was applied again (second stimulation). During stimulations, the majority of the individual scratching cycle durations were reduced $(E)$. At cessation of stimulations, the rhythm frequency returned to a lower value.

shown in Figure 5, two such continuous stimulations were given. The nonaveraged and averaged ENGs activities during the first continuous stimulation are shown in Figure $5, A$ and $B$, respectively. The activity in both the extensor (SmAB) and the flexor (Sart) nerves was increased by the stimulation (compare control, dashed traces with solid traces). Figure 5, $C$ and $D$, shows that the stimulation prolonged the duration of SmAB extensor bursts but reduced the duration of Sart flexor bursts. The increase in the duration of SmAB bursts was seen only at the beginning of the stimulation, whereas the decrease in the duration of Sart bursts was seen throughout the stimulation. Accordingly, the overall effect of continuous stimulation was a reduction of the cycle duration (Fig. 5E). Such an increase in the frequency of the scratching rhythm by continuous stimulation of ankle extensor nerve was seen in four additional experiments. These preliminary experiments indicated that activation of ankle extensor group I afferents could affect the scratching rhythm. The effects were investigated further using shorter trains of stimuli delivered either during the flexion or the extension phase of the cycle. Two effects were obtained; resetting of the rhythm and extension enhancement.

\section{Resetting of the rhythm}

It is now well established that during locomotion, stimulation of extensor group I afferents during flexion can reset the rhythm to extension (for review, see Hultborn et al., 1998). The interpretation for this finding is that some of the group I reflex pathways activated by the stimulation share interneurons with the network responsible for the locomotor rhythm. Although there are many similarities between locomotion and scratching, it is still unresolved whether both behaviors rely on the same basic network for the rhythm generation. Some indirect evidence suggests that group I afferents can reset the scratching rhythm (Baev et al., 1991). In this series of experiments, we wanted to determine whether stimulation of extensor group I afferents could reset the scratching rhythm in a similar way as during locomotion.

The ability of group I afferents to reset the scratching rhythm was investigated in seven experiments in which trains of stimuli (10 shocks, $100-300 \mathrm{~Hz}$ ) were delivered to ankle extensor nerves during the flexion phase of the fictive scratching cycle. Figure 6 (same preparation as Fig. 5) illustrates that trains of stimuli to $\mathrm{Pl}$ nerve during flexion (Fig. $6 A$ ) reset the rhythm to extension. During resetting, the ongoing activity in the flexor nerve (Sart) was interrupted while the onset of the following burst of activity in the extensor nerve (SmAB) was advanced. This is best shown in $B$, where the averaged ENGs activities in the absence (dashed traces) and during (solid traces) stimulation are superimposed. The effect of $\mathrm{Pl}$ nerve stimulation on the cycle duration is illustrated in $C$, where the mean and SD of the control cycle (un- 

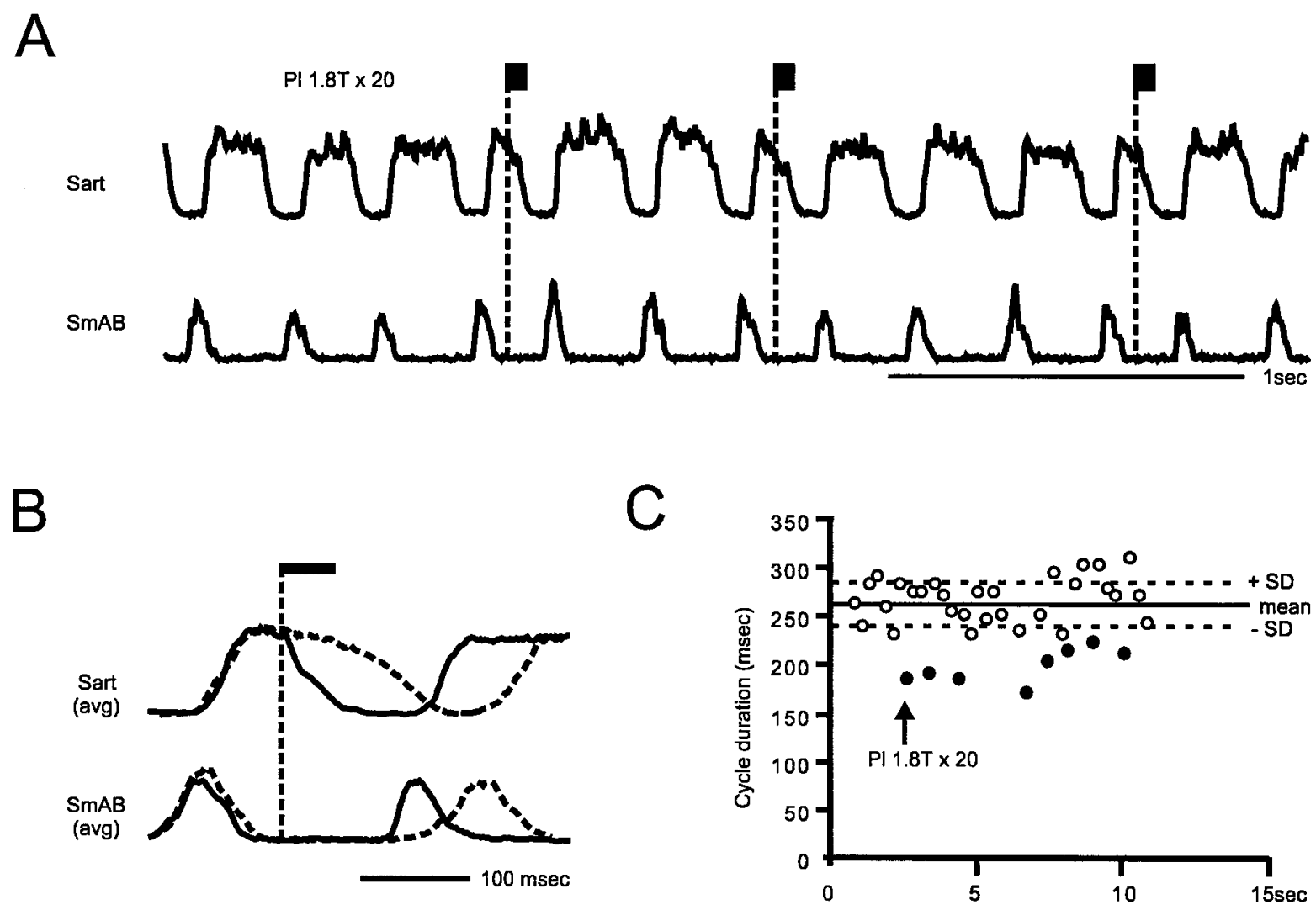

Figure 6. Activation of ankle extensor group I afferents resets the scratching rhythm. Short trains to the Pl nerve were given during the flexion phase of scratching $(1.8 \mathrm{~T} \times 20 ; 300 \mathrm{~Hz})$. A small bout of the recording session with integrated, rectified ENGs from Sart and SmAB nerves is displayed in $A$. The normalized averages $(B)$ were from eight stimulated (solid trace) and 31 control (dashed trace) cycles. $C$, The effect of Pl nerve stimulation on the scratching cycle duration for the whole recording session is shown. Stimulated cycles are represented by solid circles (arrow).

stimulated) are represented as solid and dotted horizontal lines, respectively. The control cycles (used for the calculation of the mean duration) are indicated by open circles and the stimulated cycles by filled circles. During the whole recording session (in $A$ only the portion from $2-5$ sec on the abscissa was shown), each train of stimuli reduced the cycle duration below the value of the mean $-1 \mathrm{SD}$ (mean reduction of $65 \mathrm{msec}$ ). Similar reset of the scratching rhythm to extension was found in six additional experiments after stimulation of either Pl, MG, or LGS nerves. In two experiments, trains of stimuli were also given during fictive locomotion (data not shown). In both experiments, the locomotor rhythm was also reset to extension.

\section{Increase in amplitude and duration of extensor activity}

Increases in the amplitude and/or duration of activity of extensors during fictive locomotion, [termed extension enhancement by Guertin et al. (1995)] occur when trains of stimuli to extensor group I afferents are delivered during the extension phase. In five experiments, we tested the ability of extensor group I input to produce extension enhancement during fictive scratching. Figure 7 shows the effect of short trains of stimuli applied to Pl nerve during the extension phase of scratching. During this recording session, three bouts of fictive scratching were evoked. The nonaveraged and averaged ENGs from the second bout are displayed in Figure 7, $A$ and $B$, respectively. As shown, the stimulation slightly increased the duration of both the burst in the extensor nerve $(\mathrm{SmAB})$ and the silent period in the flexor nerve (Sart). The increase in the duration of SmAB bursts for the whole recording session is illustrated in Figure $7 C$. Although the mean increase in duration was small (23 $\mathrm{msec})$, each time Pl nerve was stimulated, the duration of the individual SmAB burst (ordinate) was increased to more than the mean duration of the control burst plus $1 \mathrm{SD}$. In the remaining four experiments, a similar increase in the duration of SmAB bursts was produced by short trains of stimuli to $\mathrm{Pl}, \mathrm{MG}$, or LGS nerves. Possibly because the trains during the extension phase were of shorter duration (this phase occupied only a very small portion of the scratching cycle), the overall duration of the scratching cycle was rarely increased. This is illustrated in Figure $7 D$, in which only two of the stimulated cycles were significantly increased (last filled circle at the end of the first and third bouts). Increases in the amplitude of SmAB activity during fictive scratching were seen in only two experiments. The effects on the amplitude of extensor activity were thus less reliable than the effects on the duration. During fictive locomotion (two experiments; data not shown), trains of stimuli to ankle extensor nerves during extension increased the duration and amplitude of extensor activity and the duration of the cycle. However, both prolongations of extensor bursts without significant change in the duration of the cycle, and the more variable effects on the amplitude of extensor bursts have been reported during fictive locomotion (Guertin et al., 1995).

\section{DISCUSSION}

The present study shows that the ability of ankle extensor group I afferents to mediate oligosynaptic excitation of homonymous and synergist motoneurons is not restricted to locomotor activity. 

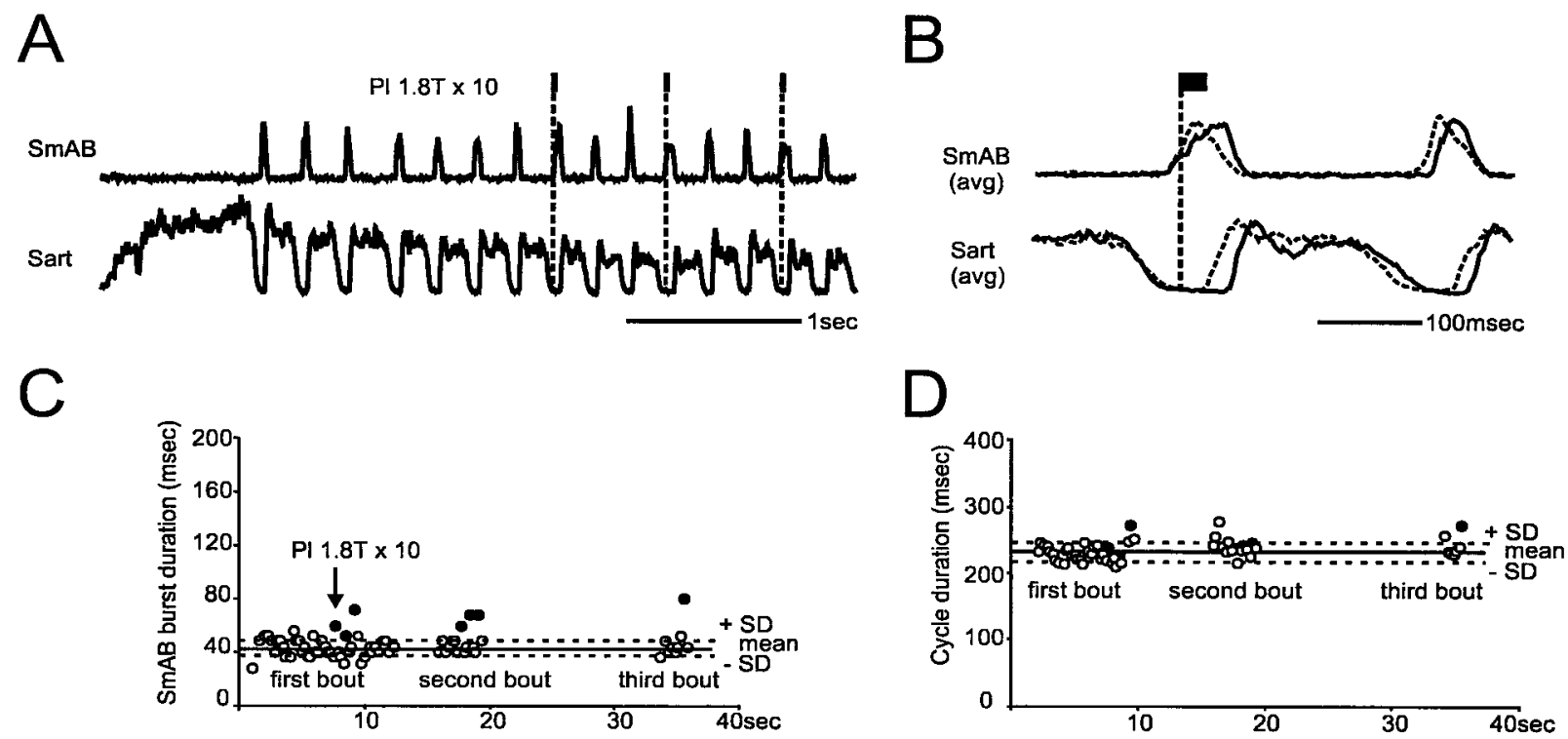

Figure 7. Ankle extensor group I input prolongs the activity of extensors. $A$, Pl nerve stimulation (trains of 10 stimuli, $200 \mathrm{~Hz}$ ) was given during the extension phase of scratching. $B$, The corresponding normalized averages showing that Pl stimulation increased the duration of SmAB burst and prolonged the silent period in Sart. The effects of the stimulation on the duration of SmAB activity and the scratching cycle for the whole recording session (three bouts of scratching) are shown in $C$ and $D$, respectively.

As during fictive locomotion, oligosynaptic excitation during fictive scratching and weight support is the result of two types of group I EPSPs (disynaptic and polysynaptic) that can be distinguished by their latency and pattern of modulation. For both EPSPs, the mean latency and the pattern of modulation during fictive scratching and weight support were similar to those during fictive locomotion. Thus, it is suggested that oligosynaptic group I EPSPs are mediated via the same reflex pathways during the three motor programs.

\section{Sources of modulation of the oligosynaptic group I EPSPs during fictive scratching and weight support}

The modulation of the oligosynaptic group I EPSPs in extensor motoneurons during fictive locomotion has been discussed extensively in previous studies (Brownstone et al., 1994; Gossard et al., 1994; McCrea et al., 1995; Angel et al., 1996) and will not be repeated here other than for comparison.

In the present study, disynaptic group I EPSPs were detected only when the motoneurons were relatively depolarized, i.e., during the extension phase of scratching and during fictive weight support. On the other hand, polysynaptic group I EPSPs, which were also detected during motoneuron depolarization, were evoked most often when the motoneurons were most hyperpolarized, i.e., during the flexion phase of scratching. Because both EPSPs can be evoked in the same motoneurons, the mechanisms responsible for the modulation are probably selective for each type of EPSP, and mechanisms such as a widespread change in motoneuronal conductance are unlikely to be involved. Selective mechanisms that may account for the modulation of the group I oligosynaptic EPSPs include (1) depolarization of the group I afferent fiber terminals, (2) activation of voltage-dependent conductances in extensor motoneurons, and (3) changes of excitability of the interneurons interposed between the group I afferents and the motoneurons. These possibilities are considered in turn.

Depolarization of primary afferent terminals (PAD) may decrease the transmission from primary afferents and, in theory, contribute to the modulation of reflex pathways. However, the PAD pattern produced in group I afferents during the induction and throughout fictive scratching (Baev and Kostyuk,1981) is mainly tonic and inconsistent with both a phasic modulation of the oligosynaptic group I reflexes or their opening during fictive scratching. More selective PAD mechanisms that could control the excitability of individual group I afferent fiber terminals while leaving others unaffected have been reported (Quevedo et al., 1997; Lomeli et al., 1998). However, it remains unknown whether such mechanisms are operational during locomotion, scratching, or weight support.

An activation of voltage-dependent conductances by input to motoneurons from the interneurons responsible for the generation of the locomotor and scratching drive potentials may contribute to the modulation of the group I oligosynaptic EPSPs (Brownstone et al., 1994). There is evidence suggesting that some of the interneurons that activate the voltage-dependent conductances also mediate polysynaptic group I EPSPs (for review, see Hultborn et al., 1998). For instance, polysynaptic group I EPSPs have been shown to exhibit a nonlinear voltage dependency that is similar to that of locomotor and scratching drive potentials (Brownstone et al., 1994). Although the activation of voltagedependent conductances could contribute to the modulation of the polysynaptic group I EPSPs during fictive locomotion and scratching, it is unknown whether voltage-dependent conductances would also be activated during weight support. For the disynaptic group I EPSPs, the lack of voltage dependency (Angel et al., 1996; McCrea, 1998) suggests a different source of modulation.

A change in the excitability of the interneurons may be the most plausible mechanism for the modulation of the group I oligosynaptic EPSPs. This would be consistent with the finding that candidate interneurons for the mediation of the disynaptic group I EPSPs responded to extensor group I afferent stimulation during the extension phase of locomotion but not during the flexion phase and neither at rest (McCrea, 1998). During fictive 
scratching, the pattern of modulation of the disynaptic group I EPSPs suggests that these interneurons are unresponsive to extensor group I afferent stimulation also during the approach period and the flexion phase. For the polysynaptic group I EPSPs, our data suggest that the interneurons mediating these EPSPs are less responsive to extensor group I afferents during the approach period and the extension phase of scratching. Assuming that the interneurons also contribute to the generation of the locomotor and scratching rhythms (see previous section), their reduced responsiveness during the extension phase could be attributable to occlusion (Gossard et al., 1994). During fictive weight support, there is no reason to believe that the transmission along the polysynaptic group I reflex pathways would be occluded because the interneurons mediating polysynaptic EPSPs were activated more frequently during weight support than during the extension phase of locomotion and scratching. The higher incidence of polysynaptic EPSPs during weight support also suggests that the interneurons have a lower background activity during weight support than during the extension phase of locomotion and scratching.

\section{A common rhythm-generating network for locomotion and scratching?}

Locomotion and scratching are clearly different motor behaviors involving different movement trajectories and underlying patterns of muscle activity. Therefore, one can hardly expect that all the interneurons activated during locomotion will also be activated during scratching and vice and versa. Consistent with this idea is the recent demonstration that the interneurons that mediate cutaneous disynaptic EPSPs in extensor motoneurons can be activated during fictive locomotion but not during scratching (Degtyarenko et al., 1998). However, this does not exclude that the neuronal network responsible for generating the rhythm during locomotion and scratching share common interneurons.

The idea of a common network for the generation of both the locomotion and the scratching rhythms has been proposed earlier by Orlovsky and collaborators (for review, see Gelfand et al., 1988). Their hypothesis was based mainly on two findings: (1) a similar location for the rhythmically active spinal interneurons during locomotion and scratching and (2) the preserved phase locked activity of individual interneurons during the transition from scratching to locomotor activity. The present finding of a reset of the scratching rhythm by activation of extensor group I afferents may be seen as additional evidence. Although reset of the rhythm indicates that extensor group I afferents have access to the scratching-generating network, the fact that the rhythm is reset to extension, as it is during locomotion, suggests further that this resetting occurs through the same population of interneurons.

\section{Functional relevance}

The present experiments show that the excitatory group I reflex pathways are open for transmission during fictive scratching and weight support, providing us with a neuronal substrate for excitatory feedback from extensor group I afferents during these activities. The importance of the excitatory group I reflexes during real scratching and weight support will depend, however, on the amount of activity in the primary afferents. Unfortunately, there is little information on this, particularly for group Ib afferents, which are believed to represent the main input to these reflex pathways (see introductory remarks). We know that during real locomotion, group Ib afferents monitor the changes in muscle force (Prochazka and Gorassini, 1998a,b), but it has yet to be determined how these changes compare with the changes in muscle force during scratching and weight support. Existing estimates of ankle extensor tendon force during real scratching (Kuhta and Smith, 1990; Carlson-Kuhta and Smith, 1994) indicate that this force is similar to that measured during quiet standing and $\sim 70 \%$ of the tendon force measured during walking (Walmsley et al., 1978). This suggests that the force produced by the contraction of ankle extensors during both real scratching and standing is significant and probably sufficient to justify a need for excitatory feedback from group Ib afferents.

Excitatory feedback from extensor group I afferents during real scratching may be used to adjust the onset and duration of hindlimb extensors (Kuhta and Smith, 1990). Our findings (Fig. 6) strongly support such a role for group I excitatory reflexes in the timing of extensor muscles during the rhythmic period of scratching. Activation of extensor group I afferents can also produce widespread excitation of extensor muscles in intact standing cats and contribute to reflex reinforcement of weight support (Pratt, 1995). According to our data, such reflex reinforcement could be mediated by the group I oligosynaptic reflex pathways.

\section{REFERENCES}

Angel MJ, Guertin P, Jiménez I, McCrea DA (1996) Group I extensor afferents evoke disynaptic EPSPs in cat hindlimb extensor motoneurons during fictive locomotion. J Physiol (Lond) 494:851-61.

Baev KV, Kostyuk PG (1981) Primary afferent depolarisation evoked by the activity of spinal scratching generator. Neuroscience 6:205-215.

Baev KV, Esipenko VB, Shimansky YP (1991) Afferent control of central pattern generators: experimental analysis of scratching in the decerebrate cat. Neuroscience 40:239-256.

Berkinblit MB, Deliagina TG, Orlovsky GN, Feldman AG (1980) Activity of motoneurons during fictitious scratch reflex in the cat. Brain Res 193:427-438.

Brownstone RM, Gossard JP, Hultborn H (1994) Voltage-dependent excitation of motoneurones from spinal locomotor centres in the cat. Exp Brain Res 102:34-44.

Carlson-Kuhta P, Smith JL (1994) Coordination between head and hindlimb motions during the cat scratch response. Exp Brain Res 101:279-290.

Conway BA, Hultborn H, Kiehn O (1987) Proprioceptive inputs resets central locomotor rhythm in the spinal cord. Exp Brain Res 68:643-656.

Degtyarenko AM, Simon ES, Norden-Krichmar T, Burke RE (1998) Modulation of oligosynaptic Cutaneous and muscle afferent reflex pathways during fictive locomotion and scratching in the cat. J Neurophysiol 79:447-463.

Deliagina TG, Feldman AG, Gelfand IM, Orlovsky GN (1975) On the role of central program and afferent inflow in the control of scratching movements in the cat. Brain Res 100:297-313.

Deliagina TG, Orlovsky GN, Perret C (1981) Efferent activity during fictitious scratch reflex in the cat. J Neurophysiol 45:595-604.

Domer FR, Feldberg W (1960) Scratching movements and facilitation of the scratch reflex produced by tubocurarine in cats. J Physiol (Lond) 153:35-51.

Eccles JC, Eccles RM, Lundberg A (1957) Synaptic actions on motoneurones caused by impulses in golgi tendon organ afferents. J Physiol (Lond) 138:227-252.

Feldman AG, Orlovsky GN, Perret C (1977) Activity of muscle spindle afferents during scratching in the cat. Brain Res 129:192-196.

Gelfand IM, Orlovsky GN, Shik M (1988) Locomotion and scratching in tetrapods. In: Neural control of rhythmic movements in vertebrates (Cohen AH, Rossignol S, Grillner S, eds), pp 167-200. New York: Wiley.

Glantz SA (1981) Primer of biostatistics (Jeffers JD, Englis MR, eds). New York: McGraw-Hill.

Gossard JP, Brownstone RM, Barajon I, Hultborn H (1994) Transmission in a locomotor-related group Ib pathway from hindlimb extensor muscles in the cat. Exp Brain Res 98:213-228.

Guertin P, Angel MJ, Perreault M-C, McCrea DA (1995) Ankle exten- 
sor group I afferents excite extensors throughout the hindlimb during fictive locomotion in the cat. J Physiol (Lond) 487:197-209.

Granit R (1950) Reflex self-regulation of muscle contraction and autogenetic inhibition. J Neurophysiol 13:351-372.

Heckman CJ, Lee RH (1998) Paradoxical effects of QX-314 on persistent inward currents underlying dendritic plateau potentials in spinal motoneurons. Soc Neurosci Abstr 24:913.

Hiebert GW, Pearson KG (1999) Contribution of sensory feedback to the generation of extensor activity during walking in the decerebrate cat. J Neurophysiol 81:758-770.

Hultborn H, Conway B, Gossard J-P, Brownstone R, Fedirchuk B, Schomburg ED, Enríquez-Denton E, Perreault M-C (1998) How do we approach locomotor networks in the mammalian spinal cord? In: Neuronal mechanisms for generating locomotor activity (Kiehn O, Harris-Warrick R, Jordan L, Hultborn H, Kudo N, eds), pp 70-82. New York: Ann NY Acad Sci.

Jankowska E (1992) Interneuronal relay in spinal pathways from proprioceptors. Prog Neurobiol 38:335-78.

Kuhta PC, Smith JL (1990) Scratch responses in normal cats: hindlimb kinematics and muscle synergies. J Neurophysiol 64:1653-1667.

Loeb GE, Hoffer JA, Marks WB (1985) Activity of spindle afferents from cat anterior thigh muscles. III. Effects of external stimuli. J Neurophysiol 54:578-591.

Lomeli J, Quevedo J, Linares P, Rudomin P (1998) Local control of information flow in segmental and ascending collaterals of single afferents. Nature 395:600-604.

McCrea DA (1998) Neuronal basis of afferent-evoked enhancement of locomotor activity. In: Neuronal mechanisms for generating locomotor activity (Kiehn O, Harris-Warrick R, Jordan L, Hultborn H, Kudo N, eds), pp 216-225. New York: Ann NY Acad Sci.

McCrea DA, Shefchyk SJ, Stephens MJ, Pearson KG (1995) Disynaptic group I excitation of synergist ankle extensor motoneurones during fictive locomotion in the cat. J Physiol (Lond) 487:527-539.

Pearson KG (1995) Proprioceptive regulation of locomotion. Curr Opin Neurobiol 5:786-791.

Pearson KG, Collins DF (1993) Reversal influence of group Ib afferents from plantaris on activity in medial gastrocnemius muscle during locomotor activity. J Neurophysiol 70:1009-1017.

Pearson KG, Jiang W, Ramirez JM (1992) The use of naloxone to facilitate the generation of the locomotor rhythm in spinal cats. J Neurosci Methods 42:75-81.
Perreault M-C, Enriquez-Denton M, Hultborn H (1997) Group I afferents oligosynaptic pathways during different fictive motor programs. Soc Neurosci Abstr 23:1044.

Pratt CA (1995) Evidence of positive force feedback among hindlimb extensors in the intact standing cat. J Neurophysiol 73:2578-2583.

Prochazka A, Gillard D, Bennett DJ (1997a) Positive force feedback control of muscles. J Neurophysiol 77:3226-3236.

Prochazka A, Gillard D, Bennett DJ (1997b) Implications of positive feedback in the control of movement J Neurophysiol 77:3237-3251.

Prochazka A, Gorassini M (1998a) Models of ensemble firing of muscle spindle afferents recorded during normal locomotion in cats. J Physiol (Lond) 507:277-291.

Prochazka A, Gorassini M (1998b) Ensemble firing of muscle afferents recorded during normal locomotion in cats. J Physiol (Lond) 507:293-304.

Quevedo J, Eguibar JR, Lomeli J, Rudomin P (1997) Patterns of connectivity of spinal interneurons with single muscle afferents. Exp Brain Res 115:387-402.

Schomburg ED, Behrends HB (1978) The possibility of phasedependent monosynaptic and polysynaptic is excitation to homonymous motoneurones during fictive locomotion. Brain Res 143:533-537.

Shefchyk SJ, Stein RB, Jordan LM (1984) Synaptic transmission from muscle afferents during fictive locomotion in the mesencephalic cat. J Neurophysiol 51:986-997.

Sherrington CS (1910) Notes on the scratch reflex of the cat. Q J Exp Physiol 3:213-220.

Shik ML, Severin FV, Orlovsky GN (1966) Control of walking and running by means of electrical stimulation of the mid-brain. Biophysics USSR 11:756-765.

Talbot MJ, Sayer RJ (1996) Intracellular QX-314 inhibits calcium currents in hippocampal CA1 pyramidal neurons. J Neurophysiol 76:2120-2124.

Walmsley B, Hodgson JA, Burke RE (1978) Forces produced by medial gastrocnemius and soleus muscles during locomotion in freely moving cats. J Neurophysiol 41:1203-1216.

Whelan PJ, Pearson KG (1997) Comparison of the effects of stimulating extensor group I afferents on cycle period during walking in conscious and decerebrate cats. Exp Brain Res 117:444-452.

Whelan PJ, Hiebert GW, Pearson KG (1995) Stimulation of the group I extensors afferents prolongs the stance phase in walking cats. Exp Brain Res 103:20-30. 